\title{
EXTENDED REPORT
}

\section{Renal functional reserve is impaired in patients with systemic sclerosis without clinical signs of kidney involvement}

\author{
R Livi, L Teghini, A Pignone, S Generini, M Matucci-Cerinic, M Cagnoni
}

See end of article for authors' affiliations

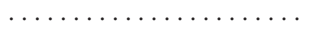

Correspondence to: Dr R Livi, Dipartimento di Medicina Interna, Sezione di Reumatologia e Nefrologia, viale Pieraccini 18, 50139 Firenze, Italy; rlivi@unifi.it

Accepted

4 February 2002
Objective: To evaluate the functional response of the kidney to an amino acid challenge (the so called renal functional reserve (RFR)) in patients with systemic sclerosis (SSc) with no clinical sign of renal involvement.

Methods: Before and after an intravenous amino acid load (Freamine III Baxter, 8.5\% solution, $4.16 \mathrm{ml} / \mathrm{min}$ for two hours), glomerular filtration rate (GFR, as creatinine clearance), effective renal plasma flow (ERPF, as para-aminohyppurate clearance), and calculated total renal vascular resistance (TRVR) were measured in 21 patients with SSc with apparently normal renal function and 10 normal controls.

Results: In basal conditions, patients had lower ERPF (403.5 (SD 43.8) v 496.4 (SD 71.3) ml/min, $\mathrm{p}<0.0002)$ and higher TRVR (10 822 (SD 2044) $v 8874$ (SD 1639) dyne/s $\left.\times \mathrm{cm}^{-5}, \mathrm{p}<0.014\right)$ than controls. The RFR, evaluated as the percentage increase of GFR after the amino acid load, was significantly reduced in patients with SSc (SSc + 1.9 (SD 18.6)\%, controls +34.8 (SD 13.9)\%; p<0.0002). However, the response of patients was not uniform. Multiple regression analysis showed that the RFR was inversely dependent on the patients' mean arterial pressure at admission and basal GFR $\left(R^{2}=65 \%\right.$, $p<0.0001$ ).

Conclusions: Most patients with SSc cannot increase renal filtration under the challenge of a protein overload. This defective renal response to the amino acid load test sustains the concept of the prevalence of vasoconstrictor over vasodilating factors in the kidney of these patients.
$\mathrm{S}$ stemic sclerosis (SSc) affects the skin and impairs the function of internal organs. The pathogenetic mechanism involves the microvascular system, leading to narrowing of the arterial lumen and vessel occlusion. The vascular damage affects the haemodynamics of several organs, in particular the kidney. In SSc, the reduction of renal blood flow and the pathological modification of the kidney have been described in detail. ${ }^{12}$

Renal involvement in SSc is often clinically silent, and it may slowly progress towards renal failure; in other cases, the breakdown of the system may be abrupt without any sentinel symptom. In any case, renal involvement heavily influences the prognosis of these patients. ${ }^{3}$

Thus, it is important to identify the haematological or urinary tools that may characterise the patients at risk of developing renal insufficiency. For this reason, we have studied the renal functional reserve ${ }^{4}$ in patients without overt signs or symptoms of renal disease to measure the ability of the kidney to increase its glomerular filtration rate (and blood flow) on stimulation with an oral protein or an intravenous amino acid load.

\section{PATIENTS AND METHODS}

Patients were selected from those patients with SSc referred to our rheumatology section during a period of six months ( 1 October 1996 -31 March, 1997). Admission criteria were diastolic blood pressure $\leqslant 90 \mathrm{~mm} \mathrm{Hg}$ at multiple measurements, serum creatinine $<92 \mu \mathrm{mol} / \mathrm{l}$, 24 hour creatinine clearance $>70 \mathrm{ml} / \mathrm{min} \times 1.73 \mathrm{~m}^{2}$, no clinical proteinuria, and normal urinary sediment. Twenty one patients with Ssc (three males and 18 females, mean age 51.1 (SD 11.6)) and 10 healthy controls (one male and nine females, mean age 46.7 (SD 16)) were admitted to the study after informed consent.
According to the criteria of LeRoy et al, ${ }^{5}$ five patients (one male, four females) had diffuse, 16 (two males, 14 females) limited cutaneous disease. The time interval between the first diagnosis of SSc and the present study ranged from 1 to 76 months (mean 28.1, median 24 months). No patient had previous evidence of scleroderma renal crisis. In all patients, oesophageal involvement was assessed by manometry; lung involvement by pulmonary function tests, high resolution CT, and carbon monoxide transfer factor (TLCO); and pulmonary hypertension by continuous wave Doppler ultrasonography. The patterns of internal organ involvement are summarised in table 1, together with the autoantibody profiles (antitopoisomerase I, anticentromere antibodies) of admitted patients.

No patient had been previously treated with ACE inhibitors or angiotensin II receptor blockers. Twelve patients were treated with transdermal nitroglycerine and seven with low dose $(10 \mathrm{mg} /$ day) oral nitrendipine for Raynaud's phenomenon. These treatments were discontinued at least two weeks before the renal tests. Patients were also instructed to avoid the use of non-steroidal anti-inflammatory drugs in the two weeks before the test.

All subjects maintained their usual diet, but were recommended to avoid excessive dietary intake of protein or salt during the week before the test.

In each subject, a 24 hour urine collection was started at home the morning before the test. Subjects were instructed to

Abbreviations: ERPF, effective renal plasma flow; GFR, glomerular filtration rate; MAP, mean arterial pressure; $\mathrm{PAH}$, para-aminohyppurate; $P C V$, packed cell volume; RFR, renal functional reserve; SSc, systemic sclerosis; TLCO, carbon monoxide transfer factor; TRVR, total renal vascular resistance; 
Table 1 Autoantibody profiles and internal organ involvement in 21 patients with systemic sclerosis

\begin{tabular}{lcc}
\hline & IcSSc & dcSSc \\
\hline Number of cases & 16 & 5 \\
Antitopoisomerase 1 antibodies & 1 & 4 \\
Anticentromere antibodies & 11 & 0 \\
Oesophageal involvement & 8 & 5 \\
Lung involvement & 6 & 4 \\
Pulmonary hypertension & 1 & 1
\end{tabular}

IcSSc, limited cutaneous systemic sclerosis; dcSSc, diffuse cutaneous systemic sclerosis.

drink $2 \mathrm{l}$ of water during the collection period, and to register the exact start and end times of this procedure. Total volume of collected urine was accurately measured in the hospital. Twenty four hour creatinine clearance, daily urinary albumin excretion, and 24 hour urinary excretions of urea and sodium were determined.

\section{Clearance studies}

All renal functional tests were performed in the morning, after an overnight fast, with the subject seated in a comfortable armchair. An antecubital vein was cannulated for the collection of venous blood samples.

According to the method described by Liedtke and Duarte, ${ }^{6}$ a priming dose of a $20 \%$ solution of sodium paraaminohyppurate (PAH), $0.05 \mathrm{ml} / \mathrm{kg}$ body weight in $50 \mathrm{ml}$ of $\mathrm{NaCl} 0.9 \%$, was given intravenously. It was followed by a sustaining infusion of the substance $(22.5 \mathrm{ml}$ of the $\mathrm{PAH}$ solution diluted to a final volume of $300 \mathrm{ml}$ with $0.9 \% \mathrm{NaCl}$, given at a constant rate of $1 \mathrm{ml} / \mathrm{min}$ ), which lasted throughout the experimental session.

Subjects drank $500 \mathrm{ml}$ of water in one hour. A first 60 minute clearance period was then started (basal period). The amino acid load test was carried out according to a previously reported protocol. ${ }^{7}$ At the end of the basal clearance period, an intravenous load of a standardised amino acid solution (Freamine III Baxter, $8.5 \%$ solution, $4.16 \mathrm{ml} / \mathrm{min}$ for two hours) was given. Two hours after the start of the load, the bladder was emptied, and a second clearance period (stimulated period) of 60 minutes in duration was started. After each micturition, an amount of water equal to urinary output was given by mouth. Urine was collected by spontaneous micturition. Subjects maintained the seated position during the whole study session.

Blood pressure was measured twice at the middle of each period with a standard mercury sphygmomanometer (Erkameter, Erka, Germany). After blood pressure measurement, venous blood samples were collected to determine plasma concentrations of creatinine and $\mathrm{PAH}$, plasma renin activity, serum concentrations of sodium, potassium and urea, serum osmolality, and packed cell volume (PCV). Blood pressure values were averaged and the means were used for calculations. Urinary volume and urinary concentrations of creatinine, $\mathrm{PAH}$, urea, sodium, and potassium were determined for each clearance period.

Creatinine was measured by autoanalyser, PAH concentrations by a colorimetric method, and sodium and potassium concentrations by flame spectrophotometry; osmolality was evaluated by depression of the freezing point with an osmometer OM 6010 (KAGAKU Co Ltd, Kyoto, Japan), PCV by a Coulter-S instrument (Coulter Electronics Inc, Hialeah, Florida); and plasma renin activity by radioimmunoassay.

Clearances of all substances were computed according to the formula:

$\mathrm{C}_{\mathrm{s}}=\left(\mathrm{U}_{\mathrm{s}} \times \mathrm{V}\right) / \mathrm{P}_{\mathrm{s}^{\prime}}$

where $U_{s}$ and $P_{s}$ are respectively the urinary and plasma concentrations of the substance $\mathrm{S}$ and $\mathrm{V}$ is the urinary volume in $\mathrm{ml} / \mathrm{min}$. Creatinine and PAH clearances were used to estimate glomerular filtration rate (GFR) and effective renal plasma flow (ERPF) respectively. All clearance values were normalised to $1.73 \mathrm{~m}^{2}$ body surface area. Filtration fraction (FF) was computed as GFR/ERPF $\times 100$. Mean arterial pressure (MAP) was calculated as diastolic blood pressure plus one third of pulse pressure. Total renal vascular resistance (TRVR) was indirectly computed from MAP, ERPF, and PCV according to the formula:

TRVR $\left(\right.$ dyne $\left./ \mathrm{s} \times \mathrm{cm}^{-5}\right)=1328($ MAP-3)/ERPF $\times(\mathrm{l} / \mathrm{PCV})$

Renal functional reserve (RFR) was calculated as the percentage GFR increase after the aminoacid load.

\section{Statistical analysis}

The statistical significance of the differences between means was evaluated by Student's $t$ test for paired or unpaired data and, when indicated, by Wilcoxon's signed rank test (paired data) or Mann-Whitney $U$ test (unpaired data). A p level $\leqslant 0.05$ was considered statistically significant. The relative power of factors affecting the renal response to amino acid load was evaluated by multiple linear regression analysis with stepwise variable selection; the assumption of normality of the distribution of the dependent variable was verified by the Kolmogorov-Smirnoff test.

\section{RESULTS}

The main clinical data of the studied subjects, as assessed immediately before the clearance studies, are reported in table 2.

At admission, patients and controls had similar 24 hour urinary volume and urinary daily excretions of urea and sodium, and they did not differ for blood pressure levels or creatinine clearance values. Clinical proteinuria was absent in

Table 2 Principal clinical characteristics of studied subjects at enrolment

\begin{tabular}{lll}
\hline & Controls & SSc patients \\
\hline Number of cases (males/females) & $10(1 / 9)$ & $21(3 / 18)$ \\
Age (years) & $46.7(16)$ & $51.1(11.6)$ \\
Weight $(\mathrm{kg})$ & $57.6(10.4)$ & $60.5(9.1)$ \\
Height $(\mathrm{cm})$ & $166.6(9.56)$ & $163.3(7.3)$ \\
Systolic pressure $(\mathrm{mm} \mathrm{Hg})$ & $123.4(15.5)$ & $125(18.4)$ \\
Diastolic pressure $(\mathrm{mm} \mathrm{Hg})$ & $73.0(5.7)$ & $74.3(7.91)$ \\
Serum creatinine $(\mu \mathrm{mol} / \mathrm{I})$ & $75(14)$ & $72(11)$ \\
24 hour creatinine clearance $\left(\mathrm{ml} / \mathrm{min} \times 1.73 \mathrm{~m}^{2}\right)$ & $83.3(14.5)$ & $81.9(16.2)$ \\
Serum urea $(\mathrm{g} / \mathrm{I})$ & $30.6(8.45)$ & $32.8(7.8)$ \\
24 hour urinary volume $(\mathrm{ml} / \mathrm{day})$ & $1634(319)$ & $1546(301)$ \\
24 hour urinary sodium (mEq/day) & $93.4(18.2)$ & $99.6(16.7)$ \\
24 hour urinary urea $(\mathrm{g} / \mathrm{day})$ & $21.1(2.7)$ & $19.5(2.3)$ \\
Plasma renin activity $(\mathrm{ng} / \mathrm{ml} / \mathrm{h})$ & $0.84(0.38)$ & $0.80(0.61)$ \\
\hline Values are mean $(\mathrm{SD})$ unless stated otherwise. & &
\end{tabular}


Table 3 Haemodynamic and renal functional variables in subjects before (basal) and after (stimulated) intravenous amino acid load

\begin{tabular}{|c|c|c|c|c|}
\hline & \multicolumn{2}{|l|}{ Basal } & \multicolumn{2}{|l|}{ Stimulated } \\
\hline & Patients & Controls & Patients & Controls \\
\hline Systolic blood pressure (mm Hg) & $126.5(16.6)$ & $123.4(15.5)$ & $127.5(18.1)$ & $121.5(14.8)$ \\
\hline Diastolic blood pressure $(\mathrm{mm} \mathrm{Hg})$ & $76.5(8.6)$ & $73.0(5.7)$ & $77.2(10.7)$ & $71.6(7.5)$ \\
\hline Mean blood pressure $(\mathrm{mm} \mathrm{Hg})$ & $93.1(10.8)$ & $89.8(8.7)$ & 93.9 (12.9) & $88.2(9.6)$ \\
\hline Creatinine clearance $\left(\mathrm{ml} / \mathrm{min} \times 1.73 \mathrm{~m}^{2} \mathrm{bsa}\right)$ & $90.7(16.8)$ & $86.9(20.7)$ & $90.9(15.7)^{* *}$ & $115.9(30.0)$ \\
\hline $\mathrm{PAH}$ clearance $\left(\mathrm{ml} / \mathrm{min} \times 1.73 \mathrm{~m}^{2} \mathrm{bsa}\right)$ & $403.5(43.8)^{* * *}$ & $496.4(71.3)$ & $406.3(61.5)^{* * *}$ & $608.1(97.1)$ \\
\hline Filtration fraction (\%) & $22.3(5.1)^{*}$ & $17.5(4.3)$ & $22.7(5.0)$ & $19.1(4.2)$ \\
\hline Total renal vascular resistance $\left(\right.$ dyne $/ \mathrm{s} \times \mathrm{cm}^{-5}$ ) & $10822(2044)^{*}$ & 8874 (1639) & $11389(2700) * * *$ & $7215(1544)$ \\
\hline Serum osmolality $(\mathrm{mmol} / \mathrm{kg})$ & $287.0(5.3)$ & $289.5(7.0)$ & $288.6(6.54)$ & $293.2(8.99)$ \\
\hline Serum sodium (mEq/l) & 141.0 (1.9) & $139.7(3.3)$ & $139.4(3.2)$ & $138.2(1.4)$ \\
\hline Urinary sodium (mEq/min) & $0.17(0.07)$ & $0.14(0.05)$ & $0.16(0.06)$ & $0.15(0.07)$ \\
\hline Fractional sodium excretion (\%) & $1.38(0.61)$ & $1.31(0.90)$ & $1.34(0.49)$ & $1.33(0.83)$ \\
\hline
\end{tabular}

all patients. Four patients had microalbuminuria (24 hour urinary albumin excretion of 27, 32, 32, and $58 \mathrm{mg}$ ).

Patients with diffuse disease did not differ from those with limited cutaneous disease for any examined variable.

Renal haemodynamic and functional data obtained for both groups before and after the amino acid load are reported in table 3 .

In basal conditions, patients and controls had similar creatinine clearance values. Effective renal plasma flow was significantly lower and total renal vascular resistance higher in patients than in controls.

In both groups, neither serum osmolality nor serum sodium concentration were significantly modified by the amino acid load. Also, systolic and diastolic blood pressures remained unchanged.

As expected, the amino acid load provoked a marked increase of mean GFR (+30.0 (SD 13.3) $\mathrm{ml} / \mathrm{min})$ and mean ERPF (+111.6 (39.6) $\mathrm{ml} / \mathrm{min})$ and a decrease in TRVR (-1659 (SD 559) dyne/s $\times \mathrm{cm}^{-5}$ ) in controls; in our patients a negligible change in these variables was found (GFR $+0.2(\mathrm{SD} 16.4) \mathrm{ml} /$ min; ERPF +2.8 (SD 68.7) ml/min, TRVR 566 (SD 2202) dyne/ $\left.\mathrm{s} \times \mathrm{cm}^{-5}\right)$. Response differences between patients and controls were statistically significant (GFR change, $p<0.0001$; ERPF change, $\mathrm{p}<0.0001$; TRVR change, $\mathrm{p}<0.005$ ).

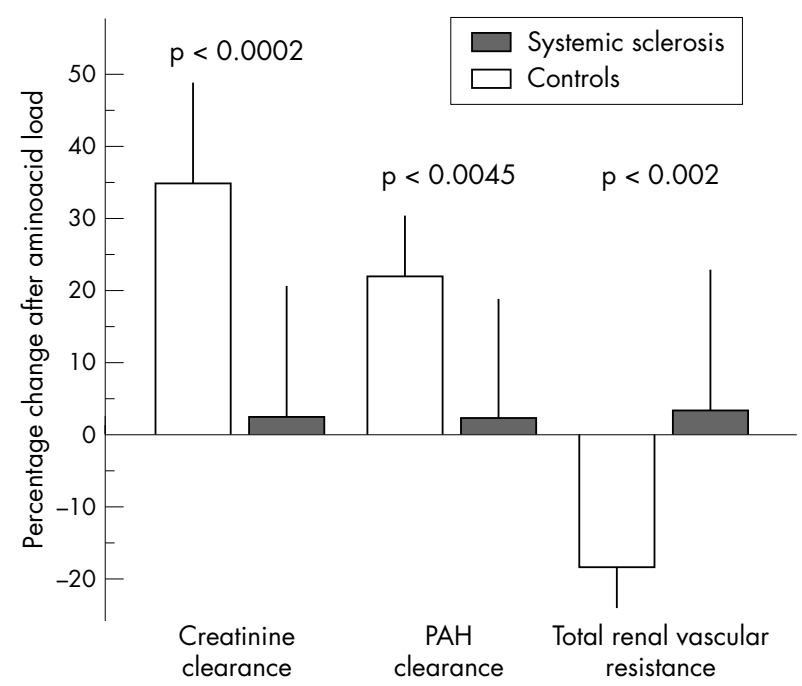

Figure 1 Effects of the amino acid load on glomerular filtration rate (creatinine clearance), effective renal plasma flow (PAH clearance), and calculated total renal vascular resistance in SSc patients and controls. Changes are expressed as percentage variation with respect to basal values.
When renal functional reserve was expressed as percentage increase with respect to basal values, controls had a 34.8 (SD 13.9 )\% rise in GFR, whereas patients showed only a 1.9 (SD $18.6) \%$ filtration increase $(\mathrm{p}<0.0002 v$ controls $)$. In controls, ERPF increased by 22.4 (7.6)\% and calculated TRVR decreased by 18 (SD 6.0)\%, whereas in patients, the corresponding changes were +1.5 (SD 16.9)\% ( $\mathrm{p}<0.0045 v$ controls $)$ and 2.55 (SD 20.3)\% $(\mathrm{p}<0.002 v$ controls, fig 1$)$.

After amino acid load, percentage increases in GFR and ERPF were significantly correlated in both patients $(r=0.60$, $\mathrm{p}<0.0045)$ and controls $(r=0.719, \mathrm{p}<0.02)$.

In both groups, absolute and fractional excretions of sodium remained virtually unchanged after the amino acid load.

Analysis of individual data showed that only six (one with microalbuminuria) out of 21 patients had a renal functional reserve comparable with that of controls, showing a GFR rise of $10 \%$ or more in stimulated conditions (fig 2).

Differences between patients with SSc with and without a renal functional reserve are reported in table 4 . Four out of five patients with diffuse cutaneous disease and 11 out of 16 patients with limited cutaneous disease showed a blunted renal functional reserve. In these 15 patients, the time between the first diagnosis of the disease and the present

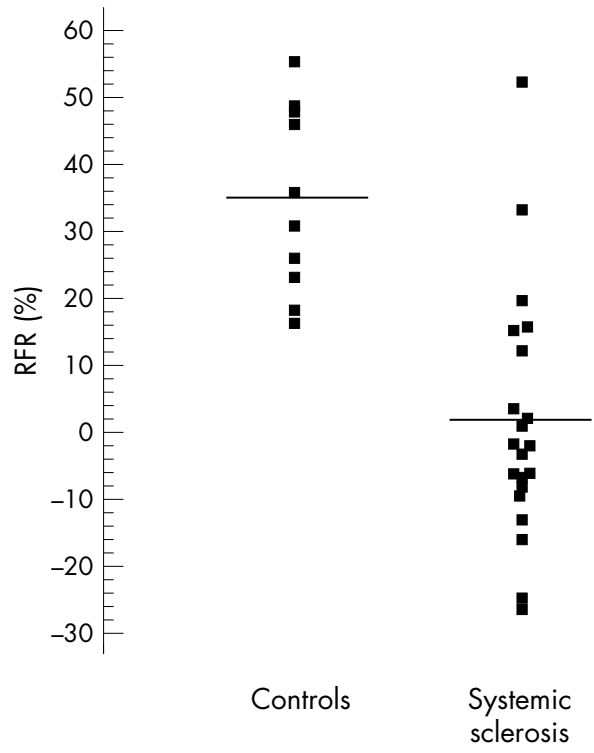

Figure 2 Distribution of the individual renal functional reserve (RFR) values obtained in SSc patients and controls. For each group, the horizontal line indicates the mean value. 
Table 4 Clinical and renal functional differences at basal evaluation in SSc patients grouped according to the renal response to aminoacid load test

\begin{tabular}{llll}
\hline & RFR $>10 \%$ & No RFR & p Value \\
\hline Diffuse/limited disease (No of patients) & $1 / 5$ & $4 / 11$ & \\
Sex (female/male) (No of patients) & $6 / 0$ & $12 / 3$ & \\
Age (years) & $50.7(12)$ & $51.3(12)$ & NS \\
Disease duration (months) & $47.2(23.3)$ & $20.5(17.5)$ & $<0.04$ \\
Creatinine clearance $\left(\mathrm{ml} / \mathrm{min} \times 1.73 \mathrm{~m}^{2}\right)$ & $83.3(14.5)$ & $81.9(16.2)$ & $<0.02$ \\
PAH clearance (ml/min $\left.\times 1.73 \mathrm{~m}^{2}\right)$ & $397(40.8)$ & $406(46.1)$ & $\mathrm{NS}$ \\
Mean blood pressure (mm Hg) & $85.5(8.4)$ & $96.1(10.3)$ & $<0.04$ \\
\hline Values are mean (SD) unless otherwise stated. & & & \\
PAH, para-amino hyppurate; RFR, renal functional reserve. & & \\
\hline
\end{tabular}

study was shorter (median 18 months $v 54.5$ months), and basal creatinine clearance and mean blood pressure were higher than in the six patients with a renal functional reserve comparable with that of controls.

Multiple regression analysis with stepwise variable selection demonstrated that the RFR was inversely dependent on basal mean arterial pressure and basal GFR in SSc patients $\left(R^{2}=65 \%, \mathrm{p}<0.0001\right)$, being progressively lower for higher basal values of GFR and MAP. These factors did not affect RFR in controls.

\section{DISCUSSION}

In patients with SSc, pathological studies have demonstrated a very high frequency of renal vascular changes, ${ }^{12}$ which have been detected also in a great proportion of SSc patients with normal renal function and normal blood pressure. ${ }^{8}$ In agreement with histopathological findings, a reduced renal blood flow has been often reported in patients with Ssc. ${ }^{19-11}$ The resistance to flow of renal arteries, explored by colour flow Doppler ultrasonography in patients with normal creatinine clearance by Rivolta et al, ${ }^{12}$ was found significantly increased in various renal vascular sites (renal artery and interlobar and cortical arteries). The present results confirm the early reduction of renal blood flow in patients with SSc with no clinical sign of renal involvement.

Before and together with the development of structural vascular wall changes, however, SSc is characterised by a functional disorder of the microcirculatory endothelium, leading to an instability of vascular tone regulation with a tendency towards vasoconstriction. ${ }^{13}$

In SSc, a defective or absent response to vasodilating stimuli represents a common feature of several vascular districts. In particular, the early phases of the disease seem to be characterised by a defect in the endothelium dependent vasodilation, which was firstly shown in the acral circulation by measuring venous compliance during the intravenous infusion of substance $\mathrm{P}^{14}$ and successively confirmed in the skin $^{15}$ and in the lung vasculature. ${ }^{16}$

With this background, we have studied the renal haemodynamic and functional response to an amino acid load in patients with SSc without clinically evident renal involvement. An oral protein ${ }^{4}$ or an intravenous amino acid load ${ }^{17}$ can provoke renal vasodilation and hyperfiltration. The absolute or percentage increase in glomerular filtration rate with respect to baseline values in response to such stimuli constitutes the RFR. $^{4}$

Our results show a blunted RFR in patients with SSc. The possible misleading effect of heavy differences in dietary sodium and protein intakes or in body hydration ${ }^{18}{ }^{19}$ could be reasonably ruled out in this study, because 24 hour urinary volume and sodium and urea excretions, evaluated the day before the test, were similar in patients and controls. In our study, controls were somewhat younger than patients, although the age difference did not reach significance.
However, it is unlikely that age could adversely affect the renal response to amino acid load, as the RFR has been shown to be maintained even in very old people. ${ }^{2021}$

It is generally accepted that the renal hyperfiltration elicited by amino acids depends on preglomerular vasodilation..$^{22}$ The intimate mechanisms underlying the activation of the renal functional reserve are not yet fully understood, although nitric oxide has been indicated as a major mediator of the phenomenon. ${ }^{24}$ Experimental studies have suggested that the renal functional reserve may reflect the intrarenal balance between angiotensin II and nitric oxide activity. ${ }^{25}{ }^{26}$ These two substances exert opposite effects at glomerular and proximal tubular level. ${ }^{27}$ In various pathophysiological conditions sharing a prevalence of angiotensin II over nitric oxide at glomerular level, the renal functional reserve seems to be markedly reduced or absent..$^{28-30}$

Our study was not addressed to evaluate eventual changes in the proposed humoral mediators of the renal haemodynamic response to amino acids. However, it is conceivable that, in patients with SSc, the lack of a renal functional reserve may unmask an imbalance between vasoconstrictor and vasodilating factors at the glomerular level.

In this study, the renal functional reserve of patients with SSc was inversely related to both blood pressure and GFR in basal conditions. The above mentioned tendency to vasoconstriction in SSc may affect the basal blood pressure level, even if it remains in the normal range as in all our patients. Thus, the observed blood pressure effect on renal functional reserve may reflect vasoconstriction.

The inverse relation with unstimulated GFR values may suggest a certain degree of basal glomerular hyperfiltration, which has been shown to reduce the renal functional reserve. ${ }^{31}$

In conclusion, our study shows clearly that, unlike normal subjects, a great proportion of patients with SSc cannot increase renal filtration when the kidney is challenged by a protein overload, even if they exhibit a normal GFR at standard clinical examination. Thus, the evaluation of kidney functional reserve may disclose an early subclinical renal abnormality in SSc. Follow up studies are required to establish if the lack of renal functional reserve in SSc is a harbinger of an increased risk of developing clinically evident renal involvement.

\section{Authors' affiliations}

R Livi, L Teghini, A Pignone, S Generini, M Matucci-Cerinic, M Cagnoni, Department of Internal Medicine, Section of Rheumatology and Nephrology, University of Firenze, Firenze, Italy

\section{REFERENCES}

1 Cannon PJ, Hassar M, Case DB, Casarella WJ, Sommers SC, LeRoy EC. The relationship of hypertension and renal failure in scleroderma (progressive systemic sclerosis) to structural and functional abnormalities of the renal cortical circulation. Medicine 1974;53:1-46. 
2 Trostle DC, Bedetti CD, Steen VD, Al-Sabbagh RM, Zee B, Medsger TA Jr. Renal vascular histology and morphometry in systemic sclerosis: $a$ case-control autopsy study. Arthritis Rheum 1988;31:393-400.

3 Shapiro AP, Medsger TA, Steen VD. Renal involvement in systemic sclerosis. In: Schrier RW, Gottshalk CW eds. Diseases of the kidney. Boston: Little, Brown and Co, 1993:2039-48.

4 Bosch JP, Saccaggi A, Lauer A, Ronco C, Belledonne M, Glabman S. Renal functional reserve in humans. Effect of protein intake on glomerula filtration rate. Am J Med 1983;75:943-50.

5 LeRoy EC, Black C, Fleischmajer R, Jablonska S, Krieg T, Medsger TA Jr et al. Scleroderma (systemic sclerosis): classification, subsets and pathogenesis. J Rheumatol 1988;15:202-5.

6 Liedtke RR, Duarte CG. Laboratory protocols and methods for the measurement of glomerular filtration rate and renal plasma flow. In: Duarte CG, ed. Renal function tests. Boston: Little, Brown and Co, 1980:49-63.

7 Cottone S, Vadalà A, Contorno A, Mangano MT, Zagarrigo C, Panepinto $N$, et al. The renal functional reserve in recently diagnosed essential hypertension. Clin Nephrol 1994;41:219-24.

8 Kovalchik MT, Guggenheim SJ, Silverman MH, Robertson JS, Steigerwald JC. The kidney in progressive systemic sclerosis. A prospective study. Ann Intern Med 1978;89:881-7.

9 Urai L, Szinai G, Nagy Z, Wiltner W. Renal function in scleroderma. BM 1958;ii:1264-6.

10 Gavras H, Gavras I, Cannon PJ, Brunner HR, Laragh JH. Is elevated plasma renin activity of prognostic importance in progressive systemic sclerosis? Arch Int Med 1977; 137:1554-8.

11 Clements PJ, Lachenbruch PA, Furst DE, Maxwell M, Danovitch G, Paulus HE. Abnormalities of renal physiology in systemic sclerosis. A prospective study with 10 year follow up. Arthritis Rheum 1994;37:67-74.

12 Rivolta R, Mascagni B, Berruti V, Quarto Di Palo F, Elli A, Scorza R, ef al. Renal vascular damage in systemic sclerosis patients without clinical evidence of nephropathy. Arthritis Rheum 1996;39:1030-4.

13 Kahaleh B, Matucci-Cerinic M. Raynaud's phenomenon and scleroderma. Dysregulated neuroendothelial control of vascular tone. Arthritis Rheum 1995;38:1-4

14 Matucci-Cerinic M, Pietrini U, Marabini S. Local venomotor response to intravenous infusion of substance $\mathrm{P}$ and glyceryl trinitrate in systemic sclerosis. Clin Exp Rheumatol 1990;8:561-5

15 La Civita L, Rossi M, Vagheggini G, Storino FA, Credidio L, Pasero G, et al. Microvascular involvement in systemic sclerosis: laser Doppler evaluation of reactivity to acetylcholine and sodium nitroprusside by iontophoresis. Ann Rheum Dis 1998;57:52-5
16 Cailes J, Winter S, du Bois RM, Evans TW. Defective endothelially mediated pulmonary vasodilation in systemic sclerosis. Chest 1998; 1 14:178-84

17 Graf $\mathbf{H}$, Stummvoli HF, Luger A, Prager R. Effect of aminoacid infusion on glomerular filtration rate. N Engl J Med 1983;308:159-60.

18 Ruilope LM, Rodicio J, Garcia Robles R, Sancho J, Miranda B, Granger $J P$, et al. Influence of a low sodium diet on renal response to amino acid infusions in humans. Kidney Int 1987;31:992-9.

19 Hadi-Aissa A, Bankir L, Fraysse M, Bichet DG, Laville M, Zech P, et al. Influence of the level of hydration on the renal response to a protein meal. Kidney Int 1992;42:1207-16.

20 Bohler J, Gloer D, Reetze-Bonorden P, Keller E, Schollmeyer PJ. Renal functional reserve in elderly patients. Clin Nephrol 1993:39: 145-50.

21 Fliser D, Ritz E, Franek E. Renal reserve in the elderly. Semin Nephrol $1995 ; 15: 463-7$.

22 Meyer TW, Ichikawa I, Zatz R, Brenner BM. The renal hemodynamic response to aminoacid infusion in the rat. Trans Assoc Am Physio 1983;96:76-83

23 Chan AYM, Cheng MLL, Keil LC, Myers BD. Functional response of healthy and diseased glomeruli to a large, protein-rich meal. J Clin Invest 1988:81:245-54

24 Tolins JP, Raij L. Effects of aminoacid infusion on renal hemodynamics. Role of endothelium-derived relaxing factor. Hypertension $1991 ; 17: 1045-51$

25 Gabbai FB, De Nicola L, Garcia GE, Blantz RC. Role of angiotensin in the regulation of renal response to proteins. Semin Nephrol 1995:15:396-404.

26 Garcia GE, Hammond TC, Wead LM, Mendonca MM, Brown MR, Gabbai FB. Effect of angiotensin II on the renal response to amino acid in rats. Am J Kidney Dis 1996;28:1 15-23.

27 De Nicola L, Blantz RC, Gabbai FB. Nitric oxide and angiotensin II: glomerular and tubular interaction in the rat. J Clin Invest 1992a;89: 1248-56.

28 De Nicola L, Keiser JA, Blantz RC, Gabbai FG. Angiotensin II and rena functional reserve in rats with Goldblatt hypertension. Hypertension 1992;19:790-4.

29 De Nicola L, Blantz RC, Gabbai FG. Renal functional reserve in the early stage of experimental diabetes. Diabetes 1992;41:267-73.

30 De Nicola L, Peterson OW, Obagi S, Keiser JA, Wilson CB, Gabbai FG. Renal functional reserve in experimental chronic glomerulonephritis. Nephrol Dial Transplant 1994;9:1383-9.

31 Jones SL, Viberti GC. Renal functional reserve in subjects with diabetes mellitus. Semin Nephrol 1995; 15:475-81. 